\title{
Relationship of different intensities of physical activity and quality of life in postmenopausal women
}

\author{
Juliana Felipe ${ }^{1 *}\left(\mathbb{D}\right.$, Juliana Viezel ${ }^{2}$, Andréa Dias Reis ${ }^{2}$ Emili Amice da Costa Barros ${ }^{3}$, Thais Reis Silva de Paulo ${ }^{4}$, \\ Lucas Melo Neves ${ }^{5}$ and Ismael Forte Freitas Júnior ${ }^{1}$
}

\begin{abstract}
Background: It is known that the elderly population remains most of the time in light activity. Physical activity plays a key role in the primary prevention of chronic diseases to mitigate various deleterious effects of aging and improve quality of life. The objective of the present study was to evaluate whether the time that postmenopausal women remain in light activities during the day are related to better quality of life and compare these results with the quality of life of those who remain longer in moderate intensity and vigorous activity.

Methods: This is a cross sectional study there were evaluated 102 women, aged 50 to 79 years, all postmenopausal. Physical activity was measured by triaxial accelerometers. The quality of life was assessed using a Brazilian validated version of the SF-36 questionnaire. The sample was divided in three groups (G1, G2 and G3) according to tercile of time spent per week on light, moderate and moderate+vigorous physical activity. The comparisons between groups were made by ANOVA One Way, and the relationship between variables were made through the Spearman's correlation coefficient, and the significance was set at $5 \%$.
\end{abstract}

Results: We found that the amount of time of light physical activity shows a higher correlation values compared to the moderate and moderate+vigorous physical activity $(p<0,05)$ and presented significant correlation in all domains of quality of life. Vigorous physical activity did not presented significant correlation in all domains of quality of life.

Conclusion: Our data suggests that light intensity physical activity presented influence on the quality of life of postmenopausal women.

Trial registration: (NCT02804308). Registered on 17 june 2016 (retrospectively registred).

Keywords: Quality of life, Level of physical activity, Postmenopausal women

\section{Introduction}

Menopause is the period marked by significant changes in women, including changes in body composition, with total body mass gain that occurs as a result of increased

\footnotetext{
* Correspondence: jfedfisica@gmail.com

${ }^{1}$ Center of Studies and Laboratory of Evaluation and Prescription of Motor Activities (CELAPAM), Department of Physical Education, Sao Paulo State University (UNESP) / FCT, Rua Roberto Simonsen, 305, Presidente Prudente, SP 1960-900, Brazil

Full list of author information is available at the end of the article
}

total and central body fat, but also a decrease in lean body mass $[1,2]$. Other behavioral character changes can affect directly personal and social, directly influencing the quality of life [3].

These changes cause a decrease in level of habitual physical activity and influence directly on the negative symptoms of menopause and aging in woman [4]. The American College of Sports Medicine recommends that adults perform $150 \mathrm{~min} /$ week of moderate physical activity for maintaining health [5], since studies report that

(c) The Author(s). 2020 Open Access This article is licensed under a Creative Commons Attribution 4.0 International License, which permits use, sharing, adaptation, distribution and reproduction in any medium or format, as long as you give appropriate credit to the original author(s) and the source, provide a link to the Creative Commons licence, and indicate if changes were made. The images or other third party material in this article are included in the article's Creative Commons licence, unless indicated otherwise in a credit line to the material. If material is not included in the article's Creative Commons licence and your intended use is not permitted by statutory regulation or exceeds the permitted use, you will need to obtain permission directly from the copyright holder. To view a copy of this licence, visit http://creativecommons.org/licenses/by/4.0/ The Creative Commons Public Domain Dedication waiver (http://creativecommons.org/publicdomain/zero/1.0/) applies to the data made available in this article, unless otherwise stated in a credit line to the data. 
compliance with such a recommendation will also help in maintaining body composition and will consequently result in a better quality of life [6].

Sedentary lifestyle is a condition that affects a large part of the population of postmenopausal women, further aggravating the consequences inherent to aging [4]. On the other hand, physically active people have longer longevity and lower morbidity and mortality rates.

Postmenopausal women with sedentary behavior have decreased resistance, strength, and lower limb muscle velocity [7]. In addition, muscle weakness and low cardiorespiratory capacity are responsible for a slower gait [8] and less safety. It is also a factor that decreases walking frequency in activities of daily living, generating a longer time of inactivity [9].

In this context, the symptoms and diseases related to human aging and menopause can be minimized through the practice of physical exercises, in the various intensities (mild, moderate and intense), types (aerobic, anaerobic and combined), and adoption of other healthy living habits [10].

However, it is known that the elderly population remains most of the time in mild activity and that these activities, such as walking, are more beneficial to maintaining quality of life than performing activities of moderate or vigorous intensity this population. Therefore, physical activity plays a fundamental role in the primary prevention of chronic diseases to attenuate several deleterious effects of aging [9].

In addition, mild physical activity seems to improve the psychic sphere, consequently favors a better quality of life [11]. However, little is known about the relationship between mild physical activity and the domains of quality of life in postmenopausal women, as well as the benefits provided in the different intensities (mild, moderate and moderate + vigorous) of physical activity to this population.

Therefore, the objective of the present study was to evaluate whether the time that postmenopausal women remain in mild activities during the day is related to the better quality of life and to compare these results with the quality of life of those who remain longer in moderate activity of intensity and vigorous.

\section{Methods}

\section{Sample}

This cross sectional study evaluated 102 women, aged between 50 and 79 years, all postmenopausal, who participated in the exercise intervention program developed between 2014 to 2016, at the São Paulo State University (UNESP), campus of Presidente Prudente, São Paulo. The data refers to the baseline moment of two clinical trials developed during 2014 to 2016, which had the objective investigating the effects of functional and combined training on body composition, metabolic profile, physical fitness, physical activity and QoL of postmenopausal women [12, 13].

In order to be included in these clinical trials, participants had to meet the following criteria: 1) menopausal period (no menstrual cycle for 12 consecutive months or more); 2) age between 50 and 79 years old at the day of the evaluation; 3) do not present physical limitations or any health problem that prevents to perform all evaluations or daily PA; 4) sign the consent form and formal clarification for participation in the study. The sample size calculator was used for sample inference, using a confidence level of $95 \%$, alpha error $5 \%$. A population proportion $10 \%$ and population size 207.610 (populational census of Presidente Prudente in 2010). Yielding the results for a new study of 84 woman, with 1:1 division of groups (G1 $n=28, \mathrm{G} 2 \mathrm{n}=28, \mathrm{G} 3 \mathrm{n}=28)$.

The invitation to participate in both studies was made through data base of regional cancer hospital, groups of cancer patients, and local media (radio, television and newspapers). The procedures used in this research attended the Criteria of Ethics in Research with Human Beings according to resolution n. 196/96 of the National Health Council - Brasília - DF and all subjects included in this study signed the Informed Consent form. The present study was approved by the Ethics and Research Committee of São Paulo State University (UNESP) (numbers 11,547,013.2.0000.5402 and 6,727,715.1.0000.5402/ 2015), and registered on ClinicalTrials.gov (NCT02804308) and on Brazilian registration clinical trial (RBR-85vmkz).

\section{Data collection}

\section{Physical activity}

The habitual physical activity (PA) was measured by triaxial accelerometers motion sensor Actigraph, GT3X model (Actigraph LLC, Pensacola, FL). The devices are light, small and designed to be positioned in the participant to record the movements in the three orthogonal planes. The equipment measures and records acceleration variations whose magnitudes cover approximately 0.05 to $2.5 \mathrm{~g}\left(\mathrm{~g}=9.8 \mathrm{~m} / \mathrm{s}^{2}\right)$ within a frequency range of 0.25 to $2.5 \mathrm{~Hz}$. Each data sample (counts) was summed over a particular time interval, called the epoch, of $60 \mathrm{~s}$. This period of $60 \mathrm{~s}$ was chosen because it is the most related to the pattern of activity of low intensity and long duration [9].

The volunteers were instructed to wear the device at the waist and remain with the equipment for, at least, seven full days (five weekdays and two weekend days). Participants were advised to take care of the equipment, which should be kept during daytime in the waking hours, and only removed when performing an activity with water (personal hygiene or water activities) and while sleeping. 
For analysis of accelerometer data was used the specific software, ActiLife6 - Data Analysis Software by Actigraph. It was included in the database only full days of monitoring with at least ten hours of use and participants with at least five days of monitoring.

The raw accelerometer data were translated in minutes of physical activity and its intensity was analyzed according to recommendations [10] for accelerometer triaxial. Mild physical activity (<3.00 METs) was defined as less than 1951 counts per minute; moderate physical activity between 1952 and 5724 (3.00-5.99 METs); vigorous physical activity between the range of 5725 to 9498 (6.00-8.99 METs); and very vigorous physical activity comprised in values greater than 9499 counts per minute (9 METs).

The habitual physical activity were expressed in minutes per week of mild, moderate, moderate+vigorous physical activity (MVPA), and counts per minute (the sum of counts of the three accelerometer axis divided by the time used).

\section{Quality of life}

Health-related quality of life was assessed using a Brazilian validated version of the SF-36 questionnaire [11]. This instrument contains 36 items divided into eight dimensions (functional capacity, pain, physical aspects, emotional aspects, social aspects, mental health, vitality and general health status). For each dimension, SF-36 items were coded, grouped and transformed into a scale of 0 (worst health) to 100 (best health status).

\section{Statistical analysis}

To verify the normality of the data the KolmogorovSmirnov test was used. Data are presented as descriptive statistics, expressed as means and standard deviations. The sample was divided in three groups (G1, G2 and G3) according to tercile of time spend per week in mild, moderate and MVPA. The comparisons between groups were made using the one-way ANOVA test. The Pearson correlation coefficient was used to verify the association between the time of different physical activity intensities and Qol. All analyzes were performed using the statistical package SPSS version 21.0, with a significance level set at $5 \%$.

\section{Results}

Study participants had a mean age of $62.1 \pm 7.8$ years and the proportion of mild to moderate activity was $23.2 \pm 33.5 \mathrm{~min} /$ day per week (minimum: 3.8; maximum: 245.3). That is, on average, for each minute in moderate physical activity per day, the participants performed 23 min in mild physical activity. The mean time spent in mild activity in the three groups studied presented a statistical difference $(\mathrm{f}=245.027, \mathrm{p}=<0.001)$. All the domains of QoL presented a difference, emphasizing G1 that presented higher values in almost all domains (functional capacity $(\mathrm{f}=0.172, p=0.003)$, pain $(\mathrm{f}=6.520, p=$ $0.002)$, general health status $(\mathrm{f}=25.290, p<0.001)$, vitality $(\mathrm{F}=33.496, p<0.001)$, emotional aspects $(\mathrm{f}=6.721$, $\mathrm{p}=0.002)$, mental health $(\mathrm{f}=17.348, p<0.001)$ and overall score $(\mathrm{f}=23,353, p<0.001)$ when compared to $\mathrm{G} 2$ and G3. Only in the domains limitation by physical aspects $(f=4446, p=0,014)$ and social aspects $(f=6.015$, $\mathrm{p}=0.003$ ), G1 differs only from G3 (Fig. 1).

The time spent in moderate physical activity presented statistical difference ( $\mathrm{f}=209,867, p<0.001)$ among the three groups. With regard to social and emotional domains of QoL, there were not observed differences between groups. However, for functional capacity $(\mathrm{f}=$ $0.8378, p<0.001)$, pain $(\mathrm{f}=4.177, p=0.018)$, general $(\mathrm{f}=$ $16,876, p<0.001)$, vitality $(\mathrm{f}=11.164, p<0.001)$, mental health $(\mathrm{f}=11,209, p<0.001)$ and total score $(\mathrm{f}=13.441$, $\mathrm{p}<0.001), \mathrm{G} 1$ differed from G2 and G3. In the domain limitation by physical aspects $(\mathrm{f}=6.378, p=0.002), \mathrm{G} 1$ was significant different from G3 (Table 1).

The MVPA of the participants presented a significant difference $(\mathrm{f}=219.723, \mathrm{p}<0.001)$ among the three groups. In terms of QoL, only the emotional domain did not present a difference between the groups. However, for functional domains $(\mathrm{f}=7.082, \mathrm{p}<0.001)$, limitation by physical aspects $(\mathrm{f}=5.887, p=0.004)$ pain $(\mathrm{f}=4.560$, $p=0.013)$, general health $(\mathrm{f}=17.940, \mathrm{p}<0.001)$, vitality $(\mathrm{f}=14.300, \mathrm{p}<0.001)$, mental health $(\mathrm{f}=11.570, \mathrm{p}<$ $0.001)$ score $(\mathrm{f}=14.528, \mathrm{p}<0.001) \mathrm{G} 1$ differed from $\mathrm{G} 2$ and G3. The social domain ( $\mathrm{f}=3.823, p=0.025$ ) showed a significant difference for G3 only (Fig. 2).

The time of mild PA, moderate and MVPA in postmenopausal women showed a positive and significant correlation for all domains (functional capacity, limitations by physical aspects, pain, general health, vitality, social aspects, emotional aspects, mental health and total score) of QoL. However, mild PA time presented more moderate correlations when compared to moderate and MVPA (Table 2).

\section{Discussion}

The aim of this study was to evaluate whether postmenopausal women who spend more time in mild, moderate, moderate+vigorous weekly physical activity have a better quality of life and associate the time in each of these activities with the domains of QoL. We found that women who spend more time in mild PA during day present higher values in all domains of QoL (functional capacity, limitations due to physical aspects, pain, general health, vitality, aspects social, emotional aspects, mental health), when compared to those that spend more time in moderate or MVPA. Women who spend more time in mild PA presented statistical difference to all domains of 


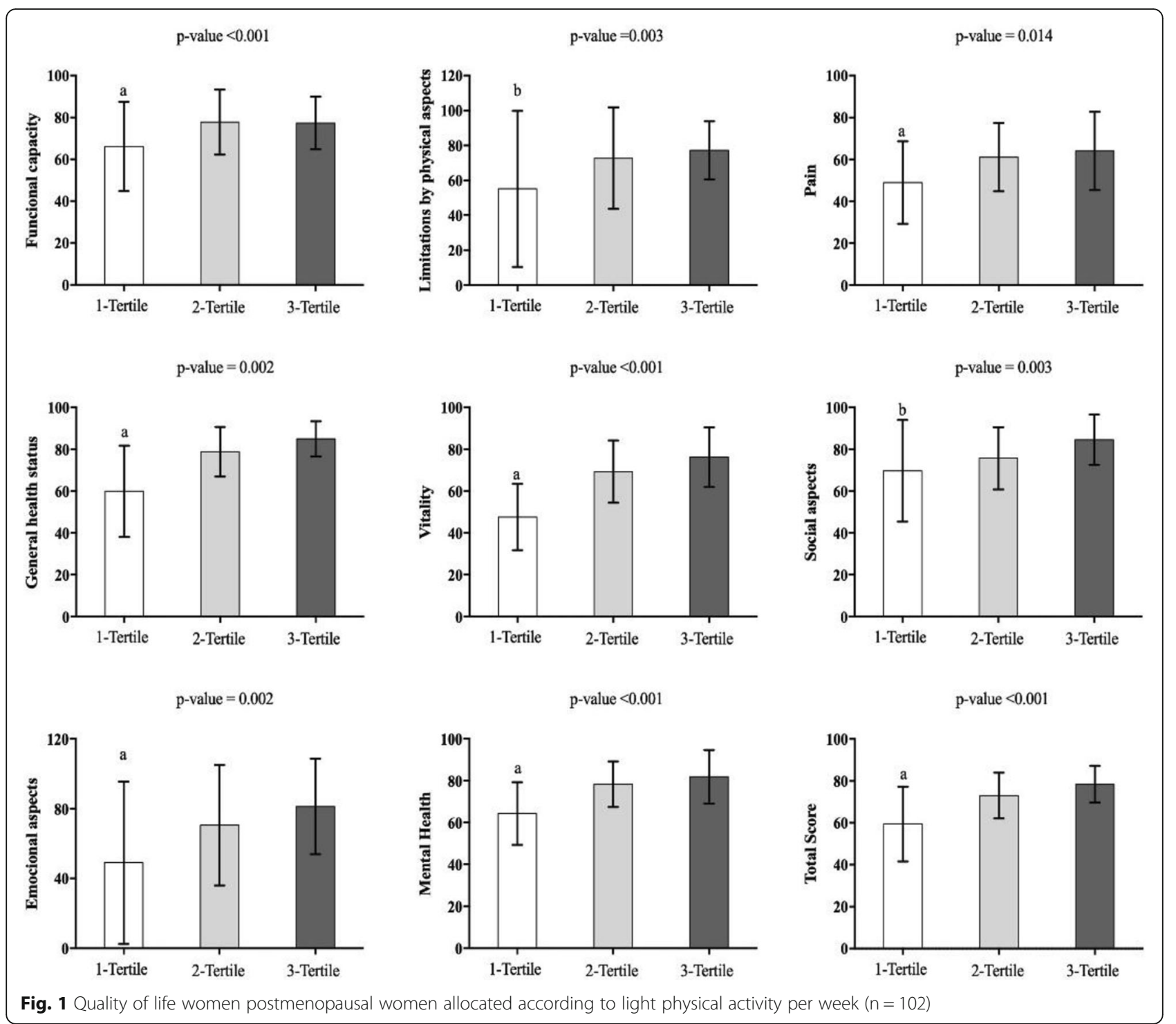

QoL. Furthermore, mild PA showed more number of positive significant correlations with QoL, suggesting that the effect of PA of mild intensity on the QoL of postmenopausal women is greater than the effects of moderate and MVPA.

It is known that the practice of PA and the reduction of sedentary behavior are associated with health in older adults, but it is recommended by the ACSM that people should perform a minimum of 150 min of moderate activity per week to improve health [15]. The study of Buman (2010) [16] converged with our findings as it verified that the quality of life of elderly is greater in those who remain more time in mild activity (as in leisure walks) than in moderate-vigorous activities.

Another study found that physically active women presented better scores in all domains of QoL and also verified that mild PA, although of low intensity, seems to contribute overall to better health conditions, having a positive impact in its psychic sphere and many characteristic symptoms, improving feelings and attitudes towards menopause and aging, which is reflected in the QoL [11]. In our study, the scores of social and emotional domains were grater for those that spend of more time in mild activity than in moderate and MVPA.

Mild PA may be more beneficial for the elderly, since according to Soares (2007) [17], for an elderly person practicing PA, it is not recommended to perform the exercise until exhaustion, since these activities can generate fatigue and pain, symptoms that can lead to larger complications, thus occurring the contrary to the desired effect.

The sedentary lifestyle means no enough physical activity to improve health and increase risk factors, and also when people are at rest. It is defined as the lack or 
Table 1 Quality of life of postmenopausal women allocated according to moderate physical activity per week $(n=102)$

\begin{tabular}{|c|c|c|c|c|c|}
\hline Variables & $\begin{array}{l}\text { G1 }(n=34) \\
\text { Mean } \pm S D\end{array}$ & $\begin{array}{l}\mathrm{G} 2(n=34) \\
\text { Mean } \pm \mathrm{SD}\end{array}$ & $\begin{array}{l}G 3(n=34) \\
\text { Mean } \pm S D\end{array}$ & $\mathrm{~F}$ & $p$-value \\
\hline \multicolumn{6}{|l|}{ Physical activity time } \\
\hline Moderate (min/week) & $72.61 \pm 41.83$ & $287.20 \pm 79.31$ & $606.56 \pm 164.45$ & 209,867 & $<0.001^{\#}$ \\
\hline \multicolumn{6}{|l|}{ Quality of life } \\
\hline Functional capacity & $50.47 \pm 21.21^{a}$ & $61.85 \pm 17.52$ & $61.82 \pm 17.15$ & 8378 & $<0.001$ \\
\hline Limitations by physical aspects & $53.68 \pm 45.69^{b}$ & $70.59 \pm 24.20$ & $80.88 \pm 18.52$ & 6378 & 0.002 \\
\hline Pain & $50.47 \pm 21.21^{a}$ & $61.85 \pm 17.52$ & $61.82 \pm 17.15$ & 4177 & 0.018 \\
\hline General health status & $61.56 \pm 22.53^{\mathrm{a}}$ & $81.29 \pm 13.98$ & $81.03 \pm 8.41$ & 16,876 & $<0.001$ \\
\hline Vitality & $51.94 \pm 19.03^{a}$ & $68.38 \pm 18.24$ & $71.91 \pm 15.32$ & 11,164 & $<0.001$ \\
\hline Social aspects & $71.38 \pm 22.76$ & $77.28 \pm 17.01$ & $81.46 \pm 14.43$ & 2571 & 0.082 \\
\hline Emotional aspects & $54.84 \pm 45.17$ & $64.72 \pm 39.30$ & $78.42 \pm 24.48$ & 2513 & 0.086 \\
\hline Mental health & $66.24 \pm 16.18^{a}$ & $76.94 \pm 14.50$ & $81.53 \pm 9.38$ & 11,209 & $<0.001$ \\
\hline Total score & $59.75 \pm 18.85^{\mathrm{a}}$ & $72.35 \pm 13.25$ & $76.94 \pm 8.35$ & 13,441 & $<0.001$ \\
\hline
\end{tabular}

${ }^{\text {" }}$ Significant difference between groups; ${ }^{a}$ Significant difference in relation to G2 and G3; ${ }^{\mathrm{b}}$ Significant difference from G3

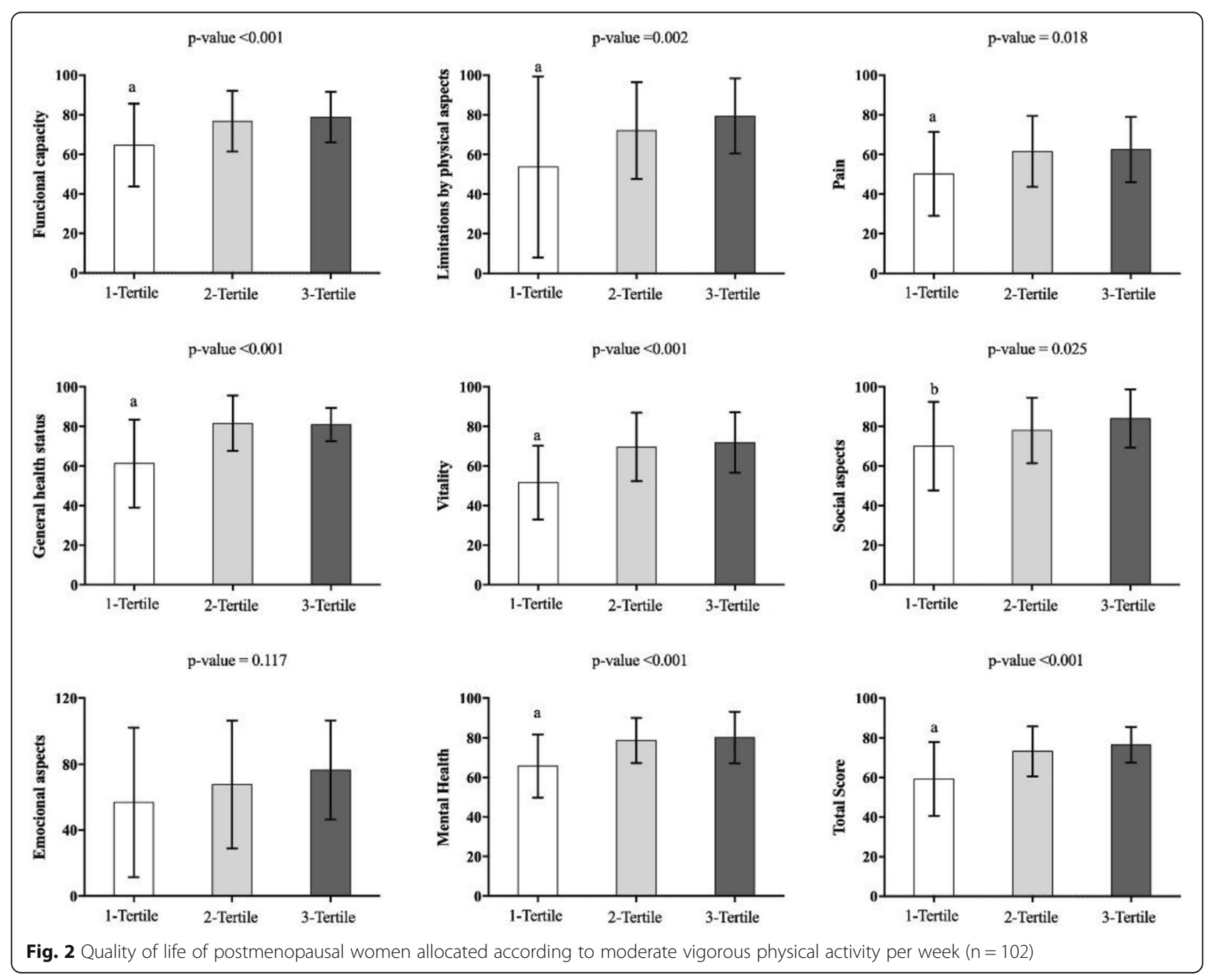


Table 2 Relationship d time physical activity and quality of life of postmenopausal women $(n=102)$

\begin{tabular}{|c|c|c|c|c|c|c|}
\hline \multirow[b]{2}{*}{ Quality of life } & \multicolumn{2}{|l|}{ Light } & \multicolumn{2}{|c|}{ Moderate } & \multicolumn{2}{|l|}{ MVPA } \\
\hline & $\bar{R}$ & $p$-value & $\bar{R}$ & $p$-value & $\bar{R}$ & $p$-value \\
\hline Functional capacity & 0.282 & 0.004 & 0,333 & $<0.001$ & 0.341 & $<0.001$ \\
\hline Limitations by physical aspects & 0.272 & 0.006 & 0.295 & 0.003 & 0.298 & 0.002 \\
\hline Pain & 0.368 & 0.001 & 0.235 & 0.017 & 0.249 & 0.012 \\
\hline General health status & $0.585^{\mathrm{a}}$ & 0.001 & $0.419^{a}$ & $<0.001$ & $0.448^{\mathrm{a}}$ & $<0.001$ \\
\hline Vitality & $0.604^{\mathrm{a}}$ & 0.001 & $0.415^{\mathrm{a}}$ & $<0.001$ & $0.448^{\mathrm{a}}$ & $<0.001$ \\
\hline Social aspects & 0.367 & 0.001 & 0.246 & 0.013 & 0.253 & 0.010 \\
\hline Emotional aspects & 0,323 & 0.001 & 0.228 & 0.021 & 0.237 & 0.016 \\
\hline Mental health & $0.480^{\mathrm{a}}$ & 0.001 & 0,395 & $<0.001$ & 0,399 & $<0.001$ \\
\hline Total score & $0.556^{\mathrm{a}}$ & 0.001 & $0.438^{a}$ & $<0.001$ & $0.450^{a}$ & $<0.001$ \\
\hline
\end{tabular}

${ }^{a}$ Moderate Correlation (FRANZBLAU, 1958) [14]

decrease of PA, the individual will spend few calories per week with occupational activities [18]. Our results demonstrate that all levels of physical activity result in a better quality of life, so it is better to perform PA, regardless of intensity, than to remain sedentary behavior for a good QoL.

In a cross-sectional population-based study, Mansikkamäki et al. [19] found that women who were physically inactive were more likely to have anxiety, depression, decreased well-being, and somatic and vasomotor symptoms, results which are opposed to those of the women who were involved in the recommended amount of PA, as they have higher self-perceptive health level and better health and overall QoL. In addition, in an Australian longitudinal study on women's health, increased PA was associated with decreased somatic symptoms [20].

This research also found that the participants of the study performed 23 min of mild activity for each minute of MVPA per week, however, there was no significant difference between the groups for body mass (data not shown). This fact may be related to the low energy expenditure of mild activities, and in order to reduce obesity, the Institute of Medicine (IOM) recommends performing 300 min of moderate to vigorous physical activity per week [21].

The practice of PA is associated to lower mortality rates in overweight or obese active individuals when compared with their sedentary pairs [22]. Thus, although longer time of mild PA does not result in a decrease in the amount of body fat, a greater active time in daily PA results in a better QoL, even if the individual remains overweight or obese [23].

The present study presents an important direction regarding the stimulus that should be given for people to remain physically active, even if it is in mild activity, as it may be more beneficial than more intense activities for postmenopausal women who are in the process of aging. In addition, another strong point of our research was the use of accelerometer, which is an objective measure that measures the amount of PA. Our results present a significant practical application that is the possibility to increase the amount of people could be in mild activity during some hours during the day, for ex. walking during working time, than wait for a leisure or rest time to exercise, that in the routine of the most the people, the time remain for it are few minutes or no time. We found that the habit to perform mild activity during the day could be better than exercise in a higher intensity for few minutes, to improve all domains of quality of life, and the importance of these finds is especially significant for aged people, for those affected by some chronic disease, mainly those that cause limitations to exercise and a compromised health-related quality of life.

Despite the importance of our results, the lack of more detailed clinical information of some variables that influence quality of life, is the main limitation. Furthermore, the study design limits interpretations due to reverse causality.

\section{Conclusion}

In conclusion, the study showed that postmenopausal women who spend higher time of mild physical activity present better all domains of quality of life compared to moderate and moderate+vigorous intensity physical activity. The quality of life involves a complex and multidimensional panorama, and presents objective and subjective aspects. From this context, it is observed the need of studies that, besides assigning value, sustain and favor the professional actions, allowing, therefore, to understand it broadly. Also, professionals in the area should also prescribe mild activity for this population in order to improve the quality of life.

\section{Abbreviations}

PA: Physical activity; QoL: Quality of life; MVPA: Moderate vigorous physical activity 


\section{Acknowledgements}

We would like to thank the participants of the study for their cooperation and authorization for data collection.

\section{Authors' contributions}

IFFJ, JF and JV contributed to the idea of this article and wrote the first draft of the manuscript. JV developed data processing, assisted in data collection and completed statistical analyzes. ADR and EACB helped writing and contributed to the review of the manuscript. TRSP and LMN assisted in data collection and contributed to the review of the manuscript. The authors read and approved the final manuscript

\section{Funding}

This work was supported by Coordination for the Improvement of Higher Education Personnel (CAPES).

\section{Availability of data and materials}

Data from the current study are available upon reasonable request to the corresponding author.

\section{Ethics approval and consent to participate}

All participants provided formal consent prior to the participation in the study. The present study was approved by the Ethics and Research Committee of São Paulo State University (UNESP) (numbers 11547013.2.0000.5402 and 6727715.1.0000.5402/2015), and registered on ClinicalTrials.gov (NCT02804308) and on Brazilian registration clinical trial (RBR-85vmkz).

\section{Consent for publication}

All the authors reviewed and approved the final manuscript.

\section{Competing interests}

The authors declare that they have no conflict of interests.

\section{Author details}

${ }^{1}$ Center of Studies and Laboratory of Evaluation and Prescription of Motor Activities (CELAPAM), Department of Physical Education, Sao Paulo State University (UNESP) / FCT, Rua Roberto Simonsen, 305, Presidente Prudente, SP 1960-900, Brazil. ²Post Graduation Program in Motricity Science, São Paulo State University (UNESP), School Technology and Science, Presidente Prudente, SP, Brazil. ${ }^{3}$ Post Graduation in Physiotherapy, São Paulo State University (UNESP), School Technology and Science, Presidente Prudente, SP, Brazil. ${ }^{4}$ Department of Physical Education, Federal University of Amazonas (UFAM), Parintins, AM, Brazil. ${ }^{5}$ School of Physical Education, University of São Paulo (USP), São Paulo, SP, Brazil.

\section{Received: 15 May 2018 Accepted: 24 April 2020}

\section{Published online: 06 May 2020}

\section{References}

1. Abildgaard J, Pedersen AT, Green CJ, et al. Menopause is associated with decreased whole body fat oxidation during exercise. Am J Physio Endocrinol Metab. 2013;304(11):E1227-36

2. Abdulnour J, Doucet $E$, Brochu $M$, et al. The effect of the menopausal transition on body composition and cardiometabolic risk factors: a MontrealOttawa new emerging team group study. Menopause. 2012;19(7):760-7.

3. Rindner $L$, et al. Reducing menopausal symptoms for women during the menopause transition using group education in a primary health care setting — a randomized controlled trial. Maturitas. 2017;98:14-9.

4. Ford K, Sowers M, Seeman TE, Greendale GA, Sternfeld B, Everson-ROSE SA. Cognitive functioning is related to physical functioning in a longitudinal study of women at midlife. Gerontology. 2010;56(3):250-8.

5. Nelson ME, Rejeski WJ, Blair SN, Duncan PW, Judge JO, King AC, et al. Physical activity and public health in older adults: recommendation from the American College of Sports Medicine and the American Heart Association. Med Sci Sports Exerc. 2007;39(8):1435-45.

6. Buonani C, Rosa CSDC, Diniz TA, Christofaro DGD, Monteiro HL, Rossi FE, Freitas Júnior IF. Prática de atividade física e composição corporal em mulheres na menopausa. Revista Brasileira de Ginecologia e Obstetrícia. 2013;35(4):153-8.
7. Morales, et al. Sedentarismo y condición física en mujeres postmenopáusicas Nutr Hosp. 2013;28(3):1053-9.

8. Verghese J, et al. Modifiable risk factors for new-onset slow gait in older adults. J Am Med Dir Assoc. 2016;17(5):421-5.

9. Busch TA, et al. Factors associated with lower gait speed among the elderly living in a developing country: a cross-sectional population-based study. BMC Geriatr. 2015;15(1):35.

10. Bouchard DR, et al. Impact of resistance training with or without caloric restriction on physical capacity in obese older women. Menopause. 2009; 16(1):66-72.

11. Tairova SO, Lorenzi RSD. Influência do exercício físico na qualidade de vida de mulheres na pós-menopausa: um estudo caso-controle. Rev. Bras. Geriatr. Gerontol. 2011;14(1):135-45.

12. Paulo TR, Winters-Stone KM, Viezel J, Rossi FE, Simões RR, Tosello G, Junior IFF. Effects of resistance plus aerobic training on body composition and metabolic markers in older breast cancer survivors undergoing aromatase inhibitor therapy. Exp Gerontol. 2018;111:210-7.

13. Neves LM, Fortaleza AC, Rossi FE, Diniz TA, Codogno JS, Gobbo LA, et al. Functional training reduces body fat and improves functional fitness and cholesterol levels in postmenopausal women: a randomized clinical trial. J Sports Med Phys Fitness. 2017;57(4):448-56.

14. Franzblau A. A primer of statistics for nonstatisticians. New York: Harcourt, Brace \& World; 1958

15. American College of Sports Medicine. ACSM's guidelines for exercise testing and prescription. 8. ed. Philadelphia: Lippincott Williams \& Wilkins; 2010.

16. Buman MP, Hekler EB, Haskell WL, et al. Objective light-intensity physical activity associations with rated health in older adults. Am J Epidemiol. 2010; 172:1155-65.

17. Soares, TRC. Os efeitos da atividade física na saúde do idoso. (Trabalho de Conclusão de Curso). Curso de Fisioterapia. Universidade Veiga de Almeida. Rio de Janeiro. 2007.

18. Guedes, Dartagnan Pinto; Hatmann, Angélica Cristine. Associação entre atividade física e qualidade de vida em idosos. Boletim Sociedade Portuguesa de Educação Física, n. 37, p. 95-108, 2017.

19. Mansikkamäki KIRSI, et al. Physical activity and menopause-related quality of life - A population-based cross-sectional study Maturitas. Maturitas is the name of the periodical. 80(1):69-74

20. Kim O, Jeon HO. Relationship between obesity, alcohol consumption, and physical activity of male office workers in South Korea. Nurs Health Sci. 2011;13(4):457-62

21. Lima DF, Levy RB, Luiz OC. Recomendações para atividade física e saúde: consensos, controvérsias e ambiguidades. Rev Panam Salud Publica. 2014 36(3):164-167.

22. Nahas MV. Atividade Física, Saúde e Qualidade de Vida. Conceitos e Sugestões para um Estilo de Vida Ativo. Londrina: Midiograf; 2001.

23. Guedes DP, Guedes J, ERP. Exercício na promoção da saúde. Londrina: Midiograf; 2008

24. Westerterp KR. Physical activity as determinant of daily energy expenditure Physiol Behav. 2008;93:1039-43. https://doi.org/10.1016/j.physbeh.2008.01.021.

25. Trost SG, Mciver KL, Pate RR. Conducting accelerometer-based activity assessments in field-based research. Med Sci Sports Exerc. 2005;37:S531.

26. Freedson PS, Melanson E, Sirard J. Calibration of the computer science and applications, Inc accelerometer. Med Sci Sports Exerc. 1998;30:777-81.

27. Ciconelli RM, et al. Tradução para a língua portuguesa e validação do questionário genérico de avaliação da qualidade de vida SF36 (Brasil SF-36). Revista Brasileira de Reumatologia. 1999;39(3).

28. Sample Size Calculator. [Internet]. 2020 [cited 2020 march 18] Available from: https://www.calculator.net/sample-size-calculator.

\section{Publisher's Note}

Springer Nature remains neutral with regard to jurisdictional claims in published maps and institutional affiliations. 